\title{
Freedom at any cost?
}

Shaun Sellars continues his series on ethical dilemmas in dentistry

which appears in every second issue of the BDJ.

I'm writing this on 21 July, just a few days after 'Freedom Day' where the government lifted the majority of COVID-19 lockdown restrictions. This is happening against the background of increasing caseloads, hospital admissions and deaths. There are currently 4,567 people in hospital with COVID-19 and 96 people died from COVID-19 yesterday. These figures will almost certainly look small by the time you read this.

At the same time, most of the dental community has been working for a year with burdensome PPE and downtime requirements. We are tired, physically and mentally. The new NHS dental standard operating procedure changes little, which is good given it allowed just 72 hours to implement those changes.

The current guidelines were produced in a time of great uncertainty. We didn't know much about SARS-CoV-2, the virus that causes COVID-19.

Transmission routes were undetermined. Vaccines were a distant hope. Dentistry was assumed to be a high-risk profession given our proximity to patients and the potential for transmission during treatment. Quite rightly, we employed the precautionary principle to ensure that everyone, staff and patients, remained as safe as possible. Although much has changed, our regulations are predominantly unaltered.

Where do we go from here? The evidence shows that COVID-19 is transmitted not through infected objects or surfaces but via aerosols. ${ }^{1}$ In addition to this, the majority of dental procedures produce little to no SARS-CoV-2-containing aerosols. ${ }^{2}$ It is breathing that spreads COVID-19 and transmission is driven by being in close proximity to COVID-19-positive people while indoors. We need to avoid breathing in infected air others have exhaled.

Ventilation and mask wearing appear to be the critical factors in this.

Dentistry is left in a tricky situation. If the risk of COVID-19 transmission via surfaces is low, then our surgical gowns and aprons are theoretically redundant. Binning these would undoubtedly alleviate some of the strain placed on the profession, particularly if you're one of the many having to work in already boiling surgeries. Similarly, if dentistry doesn't contribute to COVID-19 transmission, the division of procedures into AGPs and non-AGPs is unnecessary. No AGPs; no two-tier PPE system.

The sticking point is breathing. As we've seen, COVID-19 spreads predominantly by being in close contact with people in an indoor environment over a prolonged period. It's not hard to see why this may be

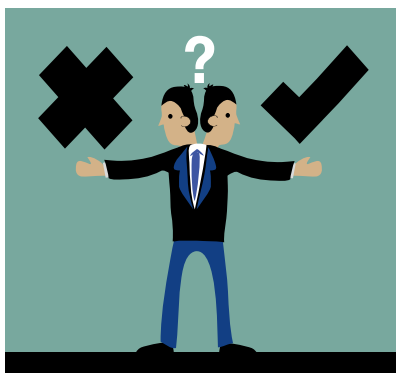

an issue for dentistry moving forward. How do we protect ourselves against an invisible enemy who seems perfectly adapted to our work environment?

One solution would be to keep our FFP3 respirators but mandate them for all patient interactions. Of course, this is ridiculous and completely impractical. More realistically, compulsory vaccination and boosters, along with ventilation regulations and ongoing testing, will probably be the only way we can get back to working in a way that even remotely resembles the dentistry of 2019.

While many will baulk at a mandatory vaccination requirement, we're already required to be vaccinated against other diseases to practise - and this minor restriction of liberty opens the door to real freedom.

\section{References}

1. Stadnytskyi V, Anfinrud P, Bax A. Breathing, speaking, coughing or sneezing: What drives transmission of SARS-CoV-2? J Intern Med 2021; doi: 10.1111/joim.13326.

2. Dudding T, Sheikh S, Gregson F et al. A clinical observational analysis of aerosol emissions from dental procedures. 2021 Available at https://www.medrxiv.org/ content/10.1101/2021.06.09.21258479v1.full (accessed July 2021).

\section{Honours, awards, appointments}

\section{BDA Board}

Chris Morris has been elected to the BDA's Principal Executive Committee (PEC) in the 2021 by-election for the vacant UK-wide seat.

Chris first qualified as a dental surgeon and practised dentistry in the UK and overseas for ten years before training as a solicitor, becoming partner at Hempsons, a national healthcare law firm, where he specialised in defending dentists.

He has served as legal adviser to the British Dental Journal for 20 years and as President of the Dental Law and Ethics Forum since 2000. His term of office will run until 31 December 2023.

\section{Committee Member}

The British Fluoridation Society (BFS) has announced that Philip Martin is joining its Executive Committee.

Dr Martin is a dental surgeon with more than 40 years' experience. He owns and operates several dental practices in Leicester after acquiring his first practice in 1990 . He has also been a Clinical Advisor to the Health Service Ombudsman since 2012. An active member of the British Dental Association (BDA), Mr Martin has served as both President and Chair of the East Midland branch. He is a long-standing member of Leicestershire Local Dental Committee (LDC), having previously served as Chair, and represented both Leicestershire and Northampton on the General Dental Practice Committee of the BDA for two terms. 